\title{
AMBIENTES DE CULTIVO, RECIPIENTES E SUBSTRATOS NA PRODUÇ̃̃O DE BIOMASSA FOLIAR E RADICULAR EM MUDAS DE MARACUJAZEİRO AMARELO EM AQUIDAUANA - MS
}

\author{
Environments of cultivation, recipients and substrates in the production of leaf \\ and root biomass of yellow passion fruit seedlings at Aquidauana - MS
}

\author{
Edilson Costa ${ }^{1}$, Paulo Ademar Martins Leal ${ }^{2}$, Léia Carla Rodrigues dos Santos ${ }^{3}$, Laura Caroline Rodrigues Vieira ${ }^{3}$
}

\section{RESUMO}

Conduziu-se este trabalho, com o objetivo de avaliar os efeitos de diferentes tipos de ambientes protegidos, tipos de recipientes e composições de substratos no acúmulo de biomassa em mudas de maracujazeiro amarelo (Passiflora edulis Sims f. flavicarpa Deg.) na região do Pantanal, nos meses de setembro a novembro de 2006. Utilizaram-se quatro ambientes protegidos, dois tipos de recipientes e três composições de substratos. Os ambientes foram: A1 (estufa plástica com filme de polietileno de baixa densidade de 150 mícrons de espessura), A2 (viveiro com tela de monofilamento preta e $50 \%$ de sombreamento), A3 (viveiro com tela aluminizada e $50 \%$ de sombreamento) e A4 (viveiro coberto com palha de buriti, palmeira nativa da região); os recipientes foram sacos de polietileno (R1) (15 X $25 \mathrm{~cm}$ ) e bandejas de poliestireno (R2), (contendo 72 células) e os substratos foram: S1 (solo + composto orgânico + vermiculita, 1:1:1 v/v), S2 (solo + composto orgânico + pó-de-serra, 1:1:1 v/v) e S3 (solo + composto orgânico + vermiculita + pó-de-serra, 1:1:1/2:1/2 v/ v). $\mathrm{O}$ experimento foi avaliado num delineamento inteiramente casualizado em esquema de parcelas subsubdivididas, com quinze repetições, onde as parcelas principais foram os ambientes de cultivo, as subparcelas foram os recipientes e as subsubparcelas foram as composições de substratos ( 4 × 2 × $3=24$ tratamentos). Foram avaliadas as massas fresca e seca da parte aérea e do sistema radicular. Os ambientes telados promoveram maiores acúmulos de biomassa em mudas de maracujazeiro amarelo produzidos em sacolas de polietileno. As sacolas de polietileno foram os recipientes que proporcionaram maiores biomassas. Os substratos que continham vermiculita promoveram melhor desenvolvimento às mudas em ambos recipientes de cultivo. O substrato com maior porcentagem de pó-de-serra não proporcionou bons resultados para a produção de mudas de maracujazeiro.

Termos para indexação: Estufa, sacolas, bandejas.

\begin{abstract}
The objective of the work was to evaluate the effects of environment, recipients, and substrate compositions in passion fruit (Passiflora edulis Sims f. flavicarpa Deg.) seedlings biomass production in Pantanal region from September to November of 2006. Experimental trials were conducted in four protected environments, in two types of containers and three different substrate compositions. The environments were: A1 (greenhouse covered with low-density, 150-microns-thick polyethylene film), A2 (monofilament black screened with mesh for 50\% of shade), A3 (aluminized screened with mesh for $50 \%$ of shade) and A4 (environment covered with straw of native coconut palm); the recipients were: polyethylene bags (R1) $(15 \times 25 \mathrm{~cm})$ and polystyrene trays (R2) (with 72 cells). There substrates were: S1 (soil + organic compost + vermiculite, 1:1: $1 \mathrm{v} / \mathrm{v})$, S2 (soil + organic compost + sawdust, 1:1: $1 \mathrm{v} / \mathrm{v}$ ) and S3 (soil + organic compost + vermiculite + sawdust, 1:1: 1/2:1/2 v/v). The experimental design was completely randomized statistical analysis in split-split-plot, with fifteen replications. The treatments in the plot were environments, in the subplots were pots, and subsubplots were substrates ( $4 \times 2 \times 3=24$ treatments). Fresh and dry mass of aerial and root system parts were evaluated. Environments with screen showed better results for seedlings of yellow passion fruit biomass in polyethylene bags. Polyethylene bags promoted higher biomasses. The substrate with vermiculite showed better results for both types of containers. The substrate with a higher percentage of sawdust showed the worst result.
\end{abstract}

Index terms: Greenhouse, bags, trays.

(Recebido em 29 de agosto de 2008 e aprovado em 9 de outubro de 2009)

\section{INTRODUÇÃO}

A produção de mudas em ambientes protegidos promove melhor crescimento, desenvolvimento da planta e melhores resultados de produção no campo (Cavalcante et al., 2002). Conforme observado por Zanella et al. (2006), a utilização de sombreamento é uma importante técnica na formação de mudas de maracujazeiro, pois afeta, diretamente, o crescimento da planta e, posteriormente, a formação do pomar.

A produção de mudas em recipientes é uma técnica empregada e difundida em diversas regiões do mundo e

'Universidade Estadual de Mato Grosso do Sul/UEMS - Unidade de Aquidauana - Rodovia Aquidauana - Cera, Km 12 - Zona rural - Cx. P. 25 - $79200-000$ Aquidauana, MS - mestrini@uems.br

${ }^{2}$ Faculdade de Engenharia Agrícola-FEAGRI/UNICAMP - Campinas, SP

${ }^{3}$ Universidade Estadual de Mato Grosso do Sul/UEMS - Aquidauana, MS 
especialmente no Brasil (Tessarioli Neto, 1995). É um sistema que deve ser preciso em sua instalação, principalmente nos seus componentes (substratos, recipientes, ambientes etc.), não acarretando redução na eficiência de produção (Minami, 1995). O recipiente mais usado para a produção de mudas de maracujá e que apresenta melhores resultados é a sacola plástica (Verdial et al., 2000; Ribeiro et al., 2005).

As dimensões dos recipientes e os substratos utilizados são as primeiras medidas a serem estudadas, buscando a garantia da produção de mudas de alta qualidade (Jesus et al., 1987). Segundo Gonçalves (1995), a produção de mudas em recipientes proporciona melhor utilização de espaço na estufa (ambiente protegido), facilitando os trabalhos de semeadura e tratos culturais.

O Estado de Mato Grosso do Sul apresenta uma economia voltada principalmente para o setor agropecuário, no entanto, os produtos hortifrutícolas são oriundos de outras Unidades da Federação. De acordo com o CEASA Campo-Grande, o Estado, no ano de 2007, foi responsável por $18,09 \%$ dos produtos agrícolas comercializados. São Paulo participou com 34,09\% e os demais Estados da Federação, como PR, SC, MG com 47,80\% dos produtos comercializados (CEASA/MS, 2008).

A partir desses dados, verifica-se a importância de pesquisas no Estado em várias fases de produção, desde a formação de mudas de qualidade até os tratamentos de pós-colheita e comercialização. David et al. (1999) afirmam que o investimento em mudas, além de ser importante componente do investimento total na fruticultura por constituir um pré-requisito fundamental ao sucesso da atividade, é também um dos itens mais expressivos, especialmente em capital.

Neste trabalho, objetivou-se avaliar os efeitos dos diferentes tipos de ambientes protegidos, recipientes e composições de substratos no acúmulo de biomassa de maracujazeiro (Passiflora edulis Sims f. flavicarpa Deg.) na região de Aquidauana/MS.

\section{MATERIAIS E MÉTODOS}

O experimento foi conduzido em área experimental da Universidade Estadual de Mato Grosso do Sul, em Aquidauana-MS, que se localiza a altitude de $174 \mathrm{~m}$, longitude de $-55,67^{\circ}$ e latitude de $-20,45^{\circ}$, entre os meses de setembro e novembro de 2006 e consistiu na produção de mudas de maracujazeiro do grupo amarelo ou azedo em ambientes protegidos.

Foram utilizados quatro ambientes protegidos: (A1) estufa plástica, tipo capela, coberta com filme plástico de polietileno de baixa densidade, 150 microns de espessura, fechada lateralmente e frontalmente com tela de sombreamento de monofilamento, malha para $50 \%$ de sombra; (A2) viveiro telado, com fechamentos na cobertura, frontal e lateral com tela de sombreamento de monofilamento, malha para 50\% de sombra; (A3) viveiro telado, com fechamentos na cobertura, frontal e lateral com tela aluminizada, malha para $50 \%$ de sombra; (A4) viveiro coberto com palha de buriti (Mauritia flexuosa L.), palmeira nativa da região. Os ambientes A1, A2 e A3, de estrutura de madeira, possuíam dimensões de 5,0m de comprimento por $5,0 \mathrm{~m}$ de largura por $2,50 \mathrm{~m}$ de pé-direito.

Foram utilizados dois tipos de recipientes: $\mathrm{R} 1$ (sacolas de polietileno, $15 \times 25 \mathrm{~cm}$ ) e R2 (bandejas de poliestireno, contendo 72 células), onde os mesmos foram acomodados em bancadas de madeira de $3,0 \mathrm{~m}$ de comprimento por $1,20 \mathrm{~m}$ de largura por $0,80 \mathrm{~m}$ de altura.

Utilizaram-se três composições de substratos: S1 (solo + composto orgânico + vermiculita, na proporção volumétrica de 1:1:1 v/v); S2 (solo + composto orgânico + pó-de-serra, na proporção volumétrica de 1:1:1 v/v) e S3 ( solo + composto orgânico + vermiculita + pó-de-serra, na proporção volumétrica de $1: 1: 1 / 2: 1 / 2 \mathrm{v} / \mathrm{v})$.

Na preparação dos substratos, o solo foi obtido da área da Unidade Universitária de Aquidauana (UUA), o composto orgânico comercial, com idade aproximada de um ano, foi obtido da empresa Organoeste®/Dourados/ MS e o pó-de-serra utilizado foi obtido de madeireiras da região com idade aproximada de um ano. Os substratos receberam as doses de $2,5 \mathrm{~kg}$ de superfosfato simples, $0,3 \mathrm{~kg}$ de cloreto de potássio e $1,5 \mathrm{~kg}$ de calcário dolomítico, com base em um volume de $1 \mathrm{~m}^{3}$, permanecendo em descanso por 31 dias, dentro dos ambientes, antes da realização da semeadura, sendo irrigados duas vezes ao dia, de manhã e de tarde.

Colocaram-se duas sementes por recipiente ou célula. A semeadura ocorreu no dia 15 de setembro de 2006, observando-se a emergência no dia 25 de setembro de 2006. Após a semeadura, quando as plantas apresentavam, em média, $5,0 \mathrm{~cm}$ de altura, foi realizado o desbaste (dia 16 de outubro de 2006), 31 dias após a semeadura (DAS), deixando apenas uma planta por recipiente ou célula. As irrigações das mudas, por meio de rega manual, ocorreram duas vezes ao dia, de manhã e a tarde.

As mudas foram avaliadas aos 50 dias após a semeadura (DAS), mensurando-se as massas frescas e secas da parte aérea e das raízes. A massa fresca foi medida em balança analítica e, posteriormente, levada a estufa para secagem até atingir peso constante. Coletaram-se as temperaturas máximas e mínimas diárias, bem como as temperaturas nos horários das 09h 00min, 12h 00min e $15 \mathrm{~h}$ 00min de cada ambiente de produção. 
A massa fresca foi medida em balança analítica, marca Bioprecisa, modelo FA2104N, com precisão de quatro casas decimais $(0,0001)$ e, posteriormente, levada à estufa com circulação de ar forçada, marca Hydrosan, para secagem à temperatura de $65^{\circ} \mathrm{C}$ por 72 horas.

Utilizou-se delineamento experimental em parcelas subsubdivididas (split-split plot), com quinze repetições. As parcelas principais foram os ambientes de cultivo, as subparcelas foram os recipientes (S) e as subsubparcelas foram as composições de substratos. Os dados foram submetidos à análise de variância e as médias ao teste de Tukey, ao nível de 5\% de probabilidade. As análises foram realizadas pelo programa computacional ESTAT (Sistema..., 1994).

\section{RESULTADO E DISCUSSÃO}

Os maiores acúmulos de biomassa em plantas de maracujazeiro ocorreram nos ambientes telados A2 (viveiro telado com sombrite ${ }^{\circledR} 50 \%$ ) e A3 (viveiro telado com aluminet ${ }^{\circledR} 50 \%$ ), no recipiente R1 (sacolas de poliestireno) e no substrato S1 (solo + composto orgânico + vermiculita) (Tabela 1). Esses resultados são referentes aos efeitos das parcelas, subparcelas e subsubparcelas e, como estes foram significativos, os interesses da avaliação se voltam para os desdobramentos e as respostas das interações entre ambientes, recipientes e substratos.

As interações entre ambientes e recipientes mostraram que o recipiente com maior volume de substrato
(R1) apresentou os maiores valores de biomassa, dentro de todos os ambientes analisados (Tabela 2). As bandejas de poliestireno (recipiente R2), por possuírem menor volume de substratos que as sacolas de polietileno, e também em função das altas temperaturas, provavelmente, promoveram maior evapotranspiração e proporcionaram plantas menores, concordando com os resultados obtidos por Mendonça et al. (2003).

Para o recipiente $\mathrm{R} 1$, os ambientes A2 e A3 promoveram os maiores acúmulos de biomassa em todos os parâmetros avaliados. No entanto, para o recipiente R2, os ambientes não diferiram (Tabela 2), evidenciando que no recipiente com maior volume houve interferência do ambiente no acúmulo de biomassa, resultado não verificado no recipiente com menor volume.

A sacola de polietileno (R1), quando comparada com a bandeja de poliestireno (R2), proporcionou os maiores valores para todos os parâmetros de biomassa. Assim, concorda-se com os comentários de Oliveira et al. (1993) e Ribeiro et al. (2005) que relataram que as sementes envolvidas por uma quantidade maior de substrato, apresentam melhor germinação e desenvolvimento. Mendonça et al. (2003) e Araújo et al. (2006), trabalhando com produção de mudas de mamão, destacaram esse tipo de recipiente quando comparado com as bandejas.

Não houve interação entre substratos e ambientes para a massa fresca foliar (MFF) e para a massa seca radicular (MSR). Para os parâmetros de massa seca foliar

Tabela 1 - Média da massa fresca da parte aérea (MFF), massa seca da parte aérea (MSF), massa fresca do sistema radicular (MFR) e massa seca do sistema radicular (MSR) em gramas, nas parcelas principais (ambientes - A), subparcelas (recipientes - R) e sub-sub-parcelas (substratos - S) avaliadas aos 50 DAS. Aquidauana - MS, 2006.

\begin{tabular}{ccccc}
\hline & MFF & MSF & MFR & MSR \\
\hline A1 & 2,47 B & 0,39 B & 0,68 B & 0,11 B \\
A2 & $4,24 \mathrm{~A}$ & $0,70 \mathrm{~A}$ & $1,02 \mathrm{~A}$ & $0,14 \mathrm{~A}$ \\
$\mathrm{~A} 3$ & $3,93 \mathrm{~A}$ & $0,64 \mathrm{~A}$ & $0,91 \mathrm{~A}$ & $0,14 \mathrm{~A}$ \\
$\mathrm{~A} 4$ & $2,29 \mathrm{~B}$ & $0,40 \mathrm{~B}$ & $0,51 \mathrm{~B}$ & $0,08 \mathrm{C}$ \\
\hline $\mathrm{CV}(\%)$ & 41,09 & 39,29 & 59,46 & 55,13 \\
\hline $\mathrm{R} 1$ & $5,82 \mathrm{~A}$ & $0,93 \mathrm{~A}$ & $1,1566 \mathrm{~A}$ & $0,17 \mathrm{~A}$ \\
$\mathrm{R} 2$ & $0,64 \mathrm{~B}$ & $0,14 \mathrm{~B}$ & $0,4015 \mathrm{~B}$ & $0,06 \mathrm{~B}$ \\
\hline $\mathrm{CV}(\%)$ & 41,40 & 40,96 & 50,87 & 46,87 \\
\hline S1 & $4,18 \mathrm{~A}$ & $0,71 \mathrm{~A}$ & $1,0797 \mathrm{~A}$ & $0,16 \mathrm{~A}$ \\
S2 & $1,82 \mathrm{C}$ & $0,272 \mathrm{C}$ & $0,3285 \mathrm{C}$ & $0,05 \mathrm{C}$ \\
S3 & $3,70 \mathrm{~B}$ & $0,63 \mathrm{~B}$ & $0,9289 \mathrm{~B}$ & $0,14 \mathrm{~B}$ \\
\hline $\mathrm{CV}(\%)$ & 37,54 & 33,75 & 40,95 & 42,46
\end{tabular}

* Médias seguidas de mesma letra, na coluna, não diferem entre si pelo teste de Tukey, a 5\% de probabilidade.

* $\mathrm{A}=$ ambientes; $\mathrm{R}=$ recipientes; $\mathrm{S}=$ substratos; $\mathrm{CV}=$ coeficiente de variação. 
(MSF) e massa fresca radicular (MFR), em todos os substratos, os ambientes A2 e A3 propiciaram melhor desenvolvimento às mudas do maracujazeiro. Em todos os ambientes, destacaram-se os substratos que continham vermiculita em sua constituição (Tabela 3).

O ambiente A1, mesmo possuindo tela lateral, apresentava frestas e recebia influência de ventos, deixando as plantas mais expostas a essa variável climática. A cobertura de filme de polietileno produzia internamente o efeito estufa, promovendo maior aquecimento e maior média de temperatura máxima do que os ambientes telados (Tabela 5), concordando com os resultados de Cunha \& Escobedo (2003) e Costa et al. (2004).

Esses fatores podem ter contribuído para uma maior evapotranspiração e, consequentemente, maior gasto de energia das plantas e, dessa forma, resultando em plantas com menor acúmulo de biomassa na estufa plástica e no viveiro com palha. Como as irrigações ocorriam duas vezes ao dia (manhã e tarde), em muitos dias, verificou-se a necessidade de aumentar o número de regas no ambiente coberto com filme de polietileno, especialmente nas bandejas (R2), pois, muitas células estavam perdendo totalmente a umidade, por volta das treze horas.

Os ambientes telados A2 e A3 proporcionaram redução na passagem de luz e permitiram a entrada de água pluvial no interior do ambiente no decorrer dos experimentos e, consequentemente, reduziram a evapotranspiração e propiciaram condições favoráveis ao desenvolvimento das mudas, promovendo maior MSF e MFR (Tabela 3). Comentários semelhantes a respeito dos ambientes telados foram realizados por Buriol et al. (1994) e Araujo et al. (2006) em experimentos com mamoeiro e alface, respectivamente. Esses ambientes, por apresentarem tela lateral, proporcionavam barreiras aos ventos fortes.

No ambiente A2, coberto com tela de monofilamento na cor preta, malha para $50 \%$ de sombra, foi necessário controlar a quantidade de água na irrigação em função da presença de fungos em todos os recipientes, possivelmente provocada pelo sombreamento, que reduziu a passagem de luz e propiciou a proliferação desses patógenos, além de ser um ambiente que permitia a entrada de água pluvial.

Pinto et al. (2007) observaram que telado aluminizado com $40 \%$ de sombreamento promoveu maior acúmulo de matéria seca em plantas de alfazema-do-Brasil [Aloysia gratissima (Gilles \& Hook.) Tronc.] do que telado com níveis de sombra de $80 \%$, evidenciando que as espécies respondem de maneira distinta ao tipo de sombreamento.

Zanella et al. (2006), avaliando o crescimento e os teores de pigmentos fotossintéticos de mudas de maracujá submetidas a diferentes níveis de sombreamento, constataram que os níveis de $50 \%$ e $80 \%$ propiciaram maiores alturas e melhores condições de crescimento às plantas. Os autores observaram que o aumento do sombreamento promoveu aumento nos teores de clorofila total e carotenóides totais, porém propiciou redução na relação clorofila a/b.

O ambiente A4, coberto com palha de buriti proporcionou resultados inferiores para os parâmetros de biomassas, comparado aos demais ambientes. Isso é explicado pela exposição das plantas aos efeitos do clima, principalmente aos ventos, os quais podem ter promovido maiores perdas de água, fazendo com que as plantas não conseguissem manter a pressão suficiente para o alongamento celular, resultando em plantas menores (Taiz \& Zeiger, 2004).

Nos desdobramentos das massas dos substratos dentro dos recipientes, observa-se que o substrato S1

Tabela 2 - Desdobramentos das análises das médias de massa fresca da parte aérea (MFF), massa seca da parte aérea (MSF), massa fresca do sistema radicular (MFR) e massa seca do sistema radicular (MSR) em gramas, dos recipientes (R) dentro dos ambientes (A) e dos ambientes (A) dentro dos recipientes (R), Aquidauana - MS, 2006.

\begin{tabular}{lllllll}
\hline & & \multicolumn{2}{c}{$\mathrm{A} 1$} & $\mathrm{~A} 2$ & $\mathrm{~A} 3$ & $\mathrm{~A} 4$ \\
\hline MFF & $\mathrm{R} 1$ & $4,4993 \mathrm{Ab}$ & $7,7027 \mathrm{Aa}$ & $7,1592 \mathrm{Aa}$ & $3,9372 \mathrm{Ab}$ \\
& $\mathrm{R} 2$ & $0,4489 \mathrm{Ba}$ & $0,7746 \mathrm{Ba}$ & $0,6997 \mathrm{Ba}$ & $0,6444 \mathrm{Ba}$ \\
MSF & $\mathrm{R} 1$ & $0,6966 \mathrm{Ab}$ & $1,2479 \mathrm{Aa}$ & $1,1493 \mathrm{Aa}$ & $0,6178 \mathrm{Ab}$ \\
& $\mathrm{R} 2$ & $0,0871 \mathrm{Ba}$ & $0,1613 \mathrm{Ba}$ & $0,1400 \mathrm{Ba}$ & $0,1863 \mathrm{Ba}$ \\
MFR & $\mathrm{R} 1$ & $1,0634 \mathrm{Ab}$ & $1,5387 \mathrm{Aa}$ & $1,4350 \mathrm{Aa}$ & $0,5891 \mathrm{Ac}$ \\
& $\mathrm{R} 2$ & $0,2884 \mathrm{Ba}$ & $0,4930 \mathrm{Ba}$ & $0,3847 \mathrm{Ba}$ & $0,4396 \mathrm{Aa}$ \\
MSR & $\mathrm{R} 1$ & $0,1634 \mathrm{Ab}$ & $0,2122 \mathrm{Aa}$ & $0,2206 \mathrm{Aa}$ & $0,0986 \mathrm{Ac}$ \\
& R2 & $0,0538 \mathrm{Ba}$ & $0,0641 \mathrm{Ba}$ & $0,0573 \mathrm{Ba}$ & $0,0665 \mathrm{Ba}$ \\
\hline
\end{tabular}

* Médias seguidas de mesma letra maiúscula na coluna e minúscula na linha, não diferem entre si pelo teste de Tukey, a 5\% de probabilidade.

* $\mathrm{A}=$ ambientes $; \mathrm{R}=$ recipientes. 
promoveu maior acúmulo de biomassa às plantas para a maioria das varáveis estudadas, com exceção da MFF nos recipientes R1 e R2, e da MSF e MSR no recipiente R2, onde o substrato S1 não diferiu do substrato S3. Para todos os substratos, o recipiente com maior capacidade (R1) proporcionou os maiores valores de biomassa (Tabela 4).

Os substratos que continham vermiculita em suas composições (S1 e S3) apresentaram melhores condições para a produção de mudas de maracujazeiro, conforme também observado por Minami (1995) e Negreiros et al. (2004). O substrato que continha pó-de-serra foi o pior testado (Tabelas 1 e 3). Substratos com vermiculita provavelmente possuíam maior densidade de poros, retendo maior quantidade de umidade e propiciando um melhor desenvolvimento do sistema radicular.

O desempenho ruim do substrato que continha maior porcentagem de pó-de-serra (S2) pode ser decorrente do tempo em que o mesmo recebeu irrigação e ficou em descanso antes da semeadura (trinta dias), pois o mesmo poderia necessitar de maior tempo para adquirir estabilidade biológica (Boff et al., 2005).

As condições favoráveis promovidas pelos ambientes telados (A2 e A3), pela sacola de polietileno (R1) e pelo substrato que continha maior quantidade de vermiculita (S1) podem ter propiciado maior acúmulo de biomassa e maior taxa de fotossíntese.

Os diferentes materiais nas coberturas dos ambientes protegidos podem ter proporcionado alterações no microclima interno (Sentelhas et al., 1998) e terem interferido nas respostas das plantas aos processos fisiológicos, como fotossíntese e transpiração (Zanella et al., 2006). Mesmo assim, as temperaturas máxima e mínima, bem como as temperaturas nos horários das $9 \mathrm{~h} \mathrm{00min,} 12 \mathrm{~h}$ 00 min e $15 \mathrm{~h} 00 \mathrm{~min}$ de cada ambiente de produção de mudas não apresentaram diferenças significativas e não afetaram o gradiente de temperatura (Tabela 5).

Tabela 3 - Desdobramentos das análises das médias de massa seca da parte aérea (MSF) e da massa fresca do sistema radicular (MFR) em gramas, dos substratos (S) dentro dos ambientes (A) e dos ambientes (A) dentro dos substratos (S), Aquidauana - MS, 2006.

\begin{tabular}{rlccccc}
\hline & \multicolumn{2}{c}{$\mathrm{A} 1$} & $\mathrm{~A} 2$ & $\mathrm{~A} 3$ & $\mathrm{~A} 4$ \\
\hline \multirow{4}{*}{ MSF } & $\mathrm{S} 1$ & $0,5336 \mathrm{Ac}$ & $0,9547 \mathrm{Aa}$ & $0,7883 \mathrm{Ab}$ & $0,5451 \mathrm{Ac}$ \\
& $\mathrm{S} 2$ & $0,2049 \mathrm{Bb}$ & $0,3782 \mathrm{Ca}$ & $0,3788 \mathrm{Ba}$ & $0,1350 \mathrm{Bb}$ \\
& $\mathrm{S} 3$ & $0,4370 \mathrm{Ab}$ & $0,7808 \mathrm{Ba}$ & $0,7669 \mathrm{Aa}$ & $0,5259 \mathrm{Ab}$ \\
& $\mathrm{S} 1$ & $1,0632 \mathrm{Aa}$ & $1,2835 \mathrm{Aa}$ & $1,1871 \mathrm{Aa}$ & $0,7849 \mathrm{Ab}$ \\
\multirow{2}{*}{ MFR } & $\mathrm{S} 2$ & $0,2918 \mathrm{Cab}$ & $0,4107 \mathrm{Bab}$ & $0,4351 \mathrm{Ba}$ & $0,1764 \mathrm{Cb}$ \\
& $\mathrm{S} 3$ & $0,6727 \mathrm{Bb}$ & $1,3534 \mathrm{Aa}$ & $1,1074 \mathrm{Aa}$ & $0,5818 \mathrm{Bb}$ \\
\hline
\end{tabular}

* Médias seguidas de mesma letra maiúscula na coluna e minúscula na linha, não diferem entre si pelo teste de Tukey, a $5 \%$ de probabilidade.

* $\mathrm{A}=$ ambientes; $\mathrm{S}=$ substratos.

Tabela 4 - Desdobramentos das análises das médias de massa fresca da parte aérea (MFF), massa seca da parte aérea (MSF), massa fresca do sistema radicular (MFR) e massa seca do sistema radicular (MSR) em gramas, dos substratos (S) dentro dos recipientes (R) e dos recipientes (R) dentro dos substratos (S), Aquidauana - MS, 2006.

\begin{tabular}{|c|c|c|c|c|}
\hline & & S1 & S2 & S3 \\
\hline \multirow[t]{2}{*}{ MFF } & $\mathrm{R} 1$ & $7,2521 \mathrm{Aa}$ & $3,4473 \mathrm{Ab}$ & 6,7745 Аа \\
\hline & $\mathrm{R} 2$ & $1,1126 \mathrm{Ba}$ & $0,1871 \mathrm{Bb}$ & $0,6259 \mathrm{Bab}$ \\
\hline \multirow[t]{2}{*}{ MSF } & $\mathrm{R} 1$ & $1,1772 \mathrm{Aa}$ & 0,5124 Ac & $1,0940 \mathrm{Ab}$ \\
\hline & $\mathrm{R} 2$ & $0,2336 \mathrm{Ba}$ & $0,0360 \mathrm{Bb}$ & $0,1614 \mathrm{Ba}$ \\
\hline \multirow[t]{2}{*}{ MFR } & $\mathrm{R} 1$ & $1,5490 \mathrm{Aa}$ & $0,5192 \mathrm{Ac}$ & $1,4014 \mathrm{Ab}$ \\
\hline & $\mathrm{R} 2$ & $0,6103 \mathrm{Ba}$ & $0,1377 \mathrm{Bc}$ & $0,4563 \mathrm{Bb}$ \\
\hline \multirow[t]{2}{*}{ MSR } & R1 & $0,2365 \mathrm{Aa}$ & 0,0808 Ac & $0,2037 \mathrm{Ab}$ \\
\hline & $\mathrm{R} 2$ & $0,0888 \mathrm{Ba}$ & $0,0215 \mathrm{Bb}$ & $0,0710 \mathrm{Ba}$ \\
\hline
\end{tabular}

* Médias seguidas de mesma letra maiúscula na coluna e minúscula na linha, não diferem entre si pelo teste de Tukey, a 5\% de probabilidade.

$* \mathrm{R}=$ recipientes; $\mathrm{S}=$ substratos. 
Tabela 5 - Médias das temperaturas $\left({ }^{\circ} \mathrm{C}\right)$ nos horários das $09 \mathrm{~h} 00 \mathrm{~min}, 12 \mathrm{~h} 00 \mathrm{~min}$ e $15 \mathrm{~h} 00 \mathrm{~min}$, temperatura média máxima e temperatura média mínima para cada ambiente (A) de produção.

\begin{tabular}{cccccc}
\hline & $09 \mathrm{~h} 00 \mathrm{~min}$ & $12 \mathrm{~h} 00 \mathrm{~min}$ & $15 \mathrm{~h} 00 \mathrm{~min}$ & T Máxima & T mínima \\
\hline $\mathrm{A} 1$ & $29,5 \mathrm{~A}$ & $33,1 \mathrm{~A}$ & $32,3 \mathrm{~A}$ & $37,1 \mathrm{~A}$ & $21,3 \mathrm{~A}$ \\
$\mathrm{~A} 2$ & $29,2 \mathrm{~A}$ & $32,5 \mathrm{~A}$ & $31,5 \mathrm{~A}$ & $35,8 \mathrm{~A}$ & $21,5 \mathrm{~A}$ \\
$\mathrm{~A} 3$ & $29,2 \mathrm{~A}$ & $32,4 \mathrm{~A}$ & $32,0 \mathrm{~A}$ & $35,7 \mathrm{~A}$ & $21,0 \mathrm{~A}$ \\
$\mathrm{~A} 4$ & $29,8 \mathrm{~A}$ & $33,2 \mathrm{~A}$ & $32,2 \mathrm{~A}$ & $36,8 \mathrm{~A}$ & $21,7 \mathrm{~A}$ \\
$\mathrm{CV}(\%)$ & 10,4 & 11,5 & 15,9 & 10,3 & 12,0 \\
\hline
\end{tabular}

* Médias seguidas de mesma letra, na coluna, não diferem entre si pelo teste de Tukey, a 5\% de probabilidade.

\section{CONCLUSÕES}

Os ambientes telados promoveram maiores acúmulos de biomassa em mudas de maracujazeiro produzidos em sacolas de polietileno.

As sacolas de polietileno foram os recipientes que proporcionaram maiores biomassas.

Os substratos que continham vermiculita promoveram melhor desenvolvimento às mudas em ambos os recipientes de cultivo.

O substrato com maior porcentagem de pó-de-serra não proporcionou bons resultados para a produção de mudas de maracujazeiro.

\section{AGRADECIMENTOS}

Os autores agradecem a Pró-Reitoria de Pesquisa e Pós-Graduação (PROPP) da Universidade Estadual de Mato Grosso do Sul (UEMS), pelo auxílio à pesquisa.

\section{REFERÊNCIAS BIBLIOGRÁFICAS}

ARAUJO, J.G.; ARAÚJO JÚNIOR, M.M.; MENEZES, R.H.N.; MARTINS, M.R.; LEMOS, R.N.S.; CERQUEIRA, M.C. Efeito do recipiente e ambiente de cultivo sobre o desenvolvimento de mudas de mamoeiro cv. Sunrise solo. Revista Brasileira de Fruticultura, Jaboticabal, v.28, n.3, p.526-529, dez. 2006.

BOFF, P.; DEBARBA, J.F.; SILVA, E.; WERNER, H. Qualidade e sanidade de mudas de cebola em função da adição de composto termófilo. Horticultura Brasileira, Brasília, v.23, n.4, p.875-880, 2005.

BURIOL, G.A.; STRECK, N.A.; GIMENES, E.S.; SCHNEIDER, F.M. Alterações micrometeorológicas causadas por túneis baixos de tela plástica preta cultivados com alface. Ciência Rural, Santa Maria, v.24, n.1, p.1-6, 1994.
CAVALCANTE, L.F.; SANTOS, J.B.; SANTOS, C.J.O.; FEITOSA FILHO, J.C.; LIMA, E.M.; CAVALCANTE, I.H.L. Germinação de sementes e crescimento inicial de maracujazeiros irrigados com água salina em diferentes volumes de substrato. Revista Brasileira de Fruticultura, Jaboticabal, v.24, n.3, 2002.

CEASA/MS. Boletim anual 2008: estatísticas de comercialização dos hortifrutigranjeiros. Disponível em: WWww.ceasa.ms.gov.bri?. Acesso em: 24 jun. 2008.

COSTA, E.; LEAL, P.M.; CARMO JUNIOR, R.R. Modelo de simulação da temperatura e umidade relativa do ar no interior da estufa plástica. Revista Engenharia Agrícola, Jaboticabal, v.24, n.1, p.57-67, 2004

CUNHA, A.R.; ESCOBEDO, J.F. Alterações micrometeorológicas causadas pela estufa plástica e seus efeitos no crescimento e produção da cultura de pimentão. Revista Brasileira de Agrometeorologia, Santa Maria, v.11, n.1, p.15-27, 2003.

DAVID, D.V.; SILVA, J.M.A.; SILVA, P.M. Diagnóstico de produção e comercialização de mudas e semente de espécies frutíferas na região Nordeste do Brasil. Viçosa, MG: FUNABE; UFV, 1999. 215p.

GONÇALVES, A.L. Recipientes embalagens e acondicionamentos de mudas de plantas ornamentais. In: MINAMI, K. (Ed.). Produção de mudas de alta qualidade em horticultura. São Paulo: [s.n.], 1995. 128p.

JESUS, R.M.; MENANDRO, M.S.; BATISTA, J.L.F.; COUTO, H.T.Z. do. Efeito do tamanho do recipiente, tipo pe substrato e sombreamento na produção de mudas de louro (Cordia trichotoma (vell.) arrab.) e gonçalo-alves (Astronium fraxinifolium Schott). Instituto de Pesquisas e Estudos Florestais, Piracicaba, n.37, p.13-19, dez. 1987. 
MENDONÇA, V.; ARAÚJO NETO, S.E.; RAMOS, J.D.; PIO, R.; GONTIJO, T.C.A. Diferentes substratos e recipientes na formação de mudas de mamoeiro 'Sunrise solo'. Revista Brasileira de Fruticultura, Jaboticabal, v.25, n.1, p.127-130, abr. 2003.

MINAMI, K. Produção de mudas em recipientes. In: . Produção de mudas de alta qualidade em horticultura. São Paulo: Fundação Salim Farah Maluf, 1995. cap.3, p.85-101.

NEGREIROS, J.R.S.; ÁLVARES, V.S.; BRAGA, L.R.; BRUCKNER, C.H. Diferentes substratos na formação de mudas de maracujazeiro-amarelo. Revista Ceres, Viçosa, v.51, n.294, p 243-249, 2004.

OLIVEIRA, R.P.; SCIVITTARO, W.B.; VASCONCELLOS, L.A.B.C. Avaliação de mudas de maracujazeiro em função do substrato e do tipo de bandeja. Scientia agricola, Piracicaba, v.50, n.2, p.261266, 1993.

PINTO, J.E.B.P.; CARDOSO, J.C.W.; CASTRO, E.M.; BERTOLUCCI, S.K.; MELO, L.A.; DOUSSEAU, S. Aspectos morfofisiológicos e conteúdo de óleo essencial de plantas de alfazema-do-Brasil em função de níveis de sombreamento. Horticultura Brasileira, Brasília, v.25, n.2, p.210-214, 2007.

RIBEIRO, M.C.C.; MORAIS, M.J.A.; SOUSA, A.H.; LINHARES, P.C.F.; BARROS JUNIOR, A.P. Produção de mudas de maracujá-amarelo com diferentes substratos e recipientes. Caatinga, Mossoró, v.18, n.3, p.155-158, jul/ set. 2005.

SENTELHAS, P.C.; VILLA NOVA, N.A.; ANGELOCCI, L.R. Efeito de diferentes tipos de cobertura, em miniestufas, na atenuação da radiação solar e da luminosidade. Revista Brasileira de Agrometeorologia, Santa Maria, v.6, n.1, p.479-481, 1998.

SISTEMA para análises estatísticas. Versão 2.0. Jaboticabal: FCAV-UNESP, 1994.

TAIZ, L.; ZEIGER, E. Fisiologia vegetal. 3ed. Porto Alegre: Artmed, 2004. 719p.

TESSARIOLI NETO, J. Recipientes, embalagens e acondicionamentos de mudas de hortaliças. In: MINAMI, K. Produção de mudas de alta qualidade em horticultura. São Paulo: T.A.Queiroz, 1995. cap.4, p.5964.

VERDIAL, M.F.L.; SANTOS, M.; TESSARIOLI NETO, J. Métodos de formação de mudas de maracujazeiro amarelo. Scentia Agricola, Piracicaba, v.57, n.4, p.795798, out./dez. 2000.

ZANELLA, F.; SONCELA, R.; LIMA, A.L.S. Formação de mudas de maracujazeiro "amarelo" sob níveis de sombreamento em Ji-Paraná/RO. Ciência e Agrotecnologia, Lavras, v.30, n.5, p.880-884, set./out. 2006. 